\title{
Suspended minerogenic particle distributions in high-energy coastal environments: Optical implications
}

\author{
Robert H. Stavn \\ Department of Biology, University of North Carolina at Greensboro, Greensboro, North Carolina, USA \\ Timothy R. Keen \\ Oceanography Division, Naval Research Laboratory, Stennis Space Center, Mississippi, USA \\ Received 16 August 2003; revised 13 February 2004; accepted 27 February 2004; published 4 May 2004.
}

[1] This paper examines suspended minerogenic particle distributions in the near-coastal ocean, Oceanside, California. The environment is dominated by resuspension of particles from a well-sorted sandy sediment. We obtain information on the suspended mineral matter from the relocatable numerical sedimentation model, TRANS98. Inputs for the model include bottom particle size distribution, wind speed, wave period and height, and near-bottom current speed. Model output is a vertical profile of mineral particle concentrations and size distributions at selected depths. The mineral particle size distribution allows the calculation of the total scattering coefficient of suspended minerogenic matter. The particle size distribution for the bed at Oceanside is approximately Gaussian lognormal in character. The predicted size distribution near bottom is a skewed Gaussian lognormal; then the distribution shifts toward the increasing importance of smaller size classes as we approach the water surface. Deeper stations maintain a lognormal character up into the surface layers while the shallower stations switch to a particle size distribution of the smallest size class being the modal class in the surface layers. Hyperbolic size distributions have been proposed for the Oceanside site from optical observations. These distributions would have a slope of 2.1 for coastal water which would decrease to as low as 1.3 for shallow nearshore stations and near the bottom. None of the proposed hyperbolic slopes provides an adequate approximation of the particle distributions predicted by TRANS98. The larger particle size classes are significantly overestimated by hyperbolic models, which causes the total scattering coefficient of the minerogenic matter to be overestimated. These results indicate that hyperbolic slope models cannot be used to retrieve particle size distributions by inversions involving the total scattering coefficient nor are they accurate estimators of the minerogenic scattering coefficient. INDEX TERMS: 4552 Oceanography: Physical: Ocean optics; 4546 Oceanography: Physical: Nearshore processes; 4863 Oceanography: Biological and Chemical: Sedimentation; 1640 Global Change: Remote sensing; KEYWORDS: particle size distributions, optical scattering, sediment resuspension

Citation: Stavn, R. H., and T. R. Keen (2004), Suspended minerogenic particle distributions in high-energy coastal environments: Optical implications, J. Geophys. Res., 109, C05005, doi:10.1029/2003JC002098.

\section{Introduction}

[2] One of the most challenging areas of ocean optics today is modeling and predicting the optical properties of the coastal ocean [Babin et al., 2003; Bukata et al., 1981; Bukata et al., 1995; Gallie and Murtha, 1992; Gould et al., 1999; Green et al., 2003; Hammond et al., 1995; Morel and Prieur, 1977; Risovic, 2002; Schoonmaker et al., 1994; Stavn and Weidemann, 1997; Stumpf and Pennock, 1989; Walker, 2001]. The reasons for this are the complexity of the optically active materials in the

Copyright 2004 by the American Geophysical Union. 0148-0227/04/2003JC002098\$09.00 coastal ocean and the highly variable dynamics of the coastal region. The optical properties of the open ocean have been described and modeled with bio-optical models [Morel and Prieur, 1977; Smith and Baker, 1978] in which the fundamental parameterization is in terms of the chlorophyll and water molecules. The assumption that the activities of living cells control the occurrence of associated organic materials, i.e., that they covary with the production of living cells, has proven useful and reasonably robust. Bio-optical models developed for the open ocean fail in the coastal region primarily because of the addition of minerogenic matter to the system and its added effect on the optical properties [Bukata et al., 1995; Gallie, and Murtha, 1992; Gordon and Morel, 1983; Stumpf and 


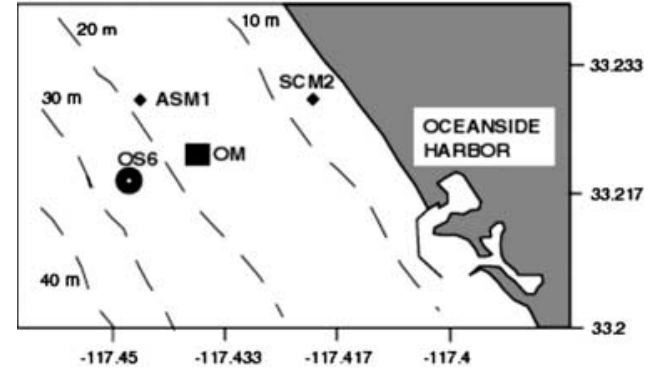

Figure 1. Map of study area and the stations referenced in this report.

Pennock, 1989; Sydor and Arnone, 1997; Tassan, 1994]. Riverine input of colored dissolved organic matter $(\mathrm{CDOM})$ can also work against the covarying nature of the suite of organic matter and make open ocean biooptical models less efficient in the coastal system [Sydor and Arnone, 1997]. Minerogenic matter is added to the coastal system from riverine input, atmospheric fallout, and bottom sediment resuspension [Keen and Stavn, 2000]. Thus we need to construct biogeo-optical models in the coastal ocean system, accounting for the optical effects of organic and mineral matter, as we have done [Keen and Stavn, 2000] (hereinafter KS).

[3] The basic premise of the coastal biogeo-optical model proposed by KS is that the absorption coefficient of the coastal hydrosol is caused predominantly by suspended organic particles (living and non-living) and dissolved organic matter [Stavn and Weidemann, 1997]. The scattering coefficient, however, is not predictable just from knowledge of the organic matter and must be determined from a summation of organic scattering coefficients and minerogenic scattering coefficients. As yet, there are few studies on or information about how to perform this partitioning of the scattering coefficient.

[4] Data on suspended mineral matter are not collected routinely, especially by the optics community. The only data commonly collected, occasionally by the optics community and often by others in the sedimentology community, are the Total Suspended Solids (TSS), [Babin et al., 2003; Tassan, 1994]. However, the TSS is not a uniform material optically, consisting of unknown quantities of both mineral and organic matter that vary temporally and spatially [Myint and Walker, 2002; Walker, 2001]. Given the relative lack of information on the concentrations of suspended mineral matter in the water column, we are getting information on suspended minerogenic matter from another source. A sedimentation model, TRANS98 [Keen and Glenn, 1998; Keen and Stavn, 2000], has been applied at a site near Oceanside, California (Figure 1) where a field sampling exercise was performed in 1995 by the Naval Research Laboratory [Roesler, 1995]. Both mineral particle size distributions and concentrations in the water column are generated by this model utilizing the particle size distribution of the bottom sediments and the physical properties of the water column. The information provided on mineral particle size distributions has allowed us to predict the minerogenic component of the scattering coefficient at this site (KS) and thus provide the information necessary for a biogeo-optical model.
[5] The TRANS98 model is used to generate the size distribution of mineral particles in the water column from the size distribution of the bottom sediments, incident wave forcing, and steady bottom currents. The total particle concentrations at specified depths in the water column that are predicted by TRANS98 are also used to calculate particle size distributions using hyperbolic slope models, which are based on the assumption that particle size distributions are approximately hyperbolic. The particle size distributions computed from the TRANS98 model and various hyperbolic size distribution models will then be compared for the Oceanside study site.

[6] The environmental causes of TRANS98-predicted sediment distributions can be understood because the numerical model solves sediment entrainment and transport equations that are based on mass conservation and laboratory observations of sediment resuspension. Conversely, the hyperbolic slope models assume a fixed distribution that is independent of environmental forcing; thus they do not permit the identification of cause-and-effect relationships. The hyperbolic slope model predictions of size distributions will be compared to the TRANS98 results. Furthermore, because of the mathematically rigorous nature of the TRANS98 calculations and the identification of processresponse relationships, we lend more credence to them. Nevertheless, we do not assume a priori that the numerical model is correct.

[7] The particle size distributions computed by the two methods, as represented by the number of particles per unit volume, are used to calculate associated minerogenic scattering coefficients from Mie theory. We will thus demonstrate that the predicted minerogenic scattering coefficients are strongly affected by the size distributions for the suspended mineral particulates, and that the use of the hyperbolic slope models can lead to erroneous estimates of the minerogenic scattering coefficient.

[8] The discussion section examines the physical causes of variability of particle size distributions and scattering coefficients with total water depth and height above the bottom. This discourse will explain why the numerical model is more accurate than hyperbolic slope models. We will demonstrate by comparison to the numerical model results that the hyperbolic size distribution models do a poor job of describing the particle size distribution in the coastal ocean. Finally, we compare the minerogenic scattering coefficients determined from the TRANS98 and hyperbolic particle size distributions with those derived from optical observations at Oceanside, California.

\section{Particle Size Distributions}

[9] The relative amount of small and large particles will significantly affect the scattering efficiency, and thus the total scattering coefficient, of the minerogenic portion of the hydrosol [Bohren and Huffman, 1983; McCartney, 1976]. McCave [1975, 1984] and Harris [1977] cogently discuss the nature of particle size distributions in the ocean and the dynamical processes that might generate them. A good mathematical summary of these issues is given by Bader [1970].

[10] There are many possible modes of expressing particle distributions based on particle diameter, volume, and 
surface area [McCave, 1975; Bader, 1970], and each has good reasons for being used. A very common mode of expressing a particle size distribution is particle concentration for a given particle diameter. Two popular methods of expressing size distributions are the cumulative number distribution function (used because Coulter counters express their data in this way) and the number distribution function [Boss et al., 2001a, 2001b; Morel and Ahn, 1991; Maffione and Dana, 1997; Shifrin, 1988; Kitchen and Zaneveld, 1990; Twardowski et al., 2001; Ulloa et al., 1994; Zaneveld and Kitchen, 1995]. The cumulative number distribution function is stated as follows:

$$
N=k D^{-c}
$$

where $N$ is the concentration (particles $/ \mathrm{m}^{3}$ ) of particles larger than the size of diameter $D, k$ is a constant related to the total particle concentration, and $c$ is a coefficient indicating an exponential trend in the size distribution. A negative $c$ coefficient indicates an exponential decay of the particle concentration as the particle diameter increases. If the $c$ coefficient is a constant, the particle size distribution is known as a hyperbolic size distribution [McCave, 1975; Bader, 1970]. If the constant $c$ has a value of 3 , the size distribution of concentration per diameter is exactly a hyperbola. This slope of 3 also defines a "Junge distribution" or a "Junge subregion" because Junge [1969] first used this function to describe the particle size distribution of aerosols. The $c$ coefficient can be obtained by plotting $\log N$ against $\log D$. The number distribution function is:

$$
\frac{d N}{d D}=K D^{-(c+1)}
$$

which is simply the derivative of equation (1). The particle concentration $d N$ for a given particle diameter $D$ is normalized to the differential diameter $d D$, which has some advantages in comparing different particle size distributions. It is important to note that the slope of equation (2) is one greater than the slope of equation (1) [McCave, 1975; Bader, 1970] and the two slopes may become confused. In this report we will utilize exclusively the slope $c$ of equation (1), the slope of the cumulative number distribution.

[11] Various investigators have reported that an approximate average to the $c$ coefficient inferred for marine particle distributions is in the range of 2.5-3.0 [Jerlov, 1976; Brun-Cottan, 1971] whereas the maximum reported range of these values is 0.7-6.0 [Jerlov, 1976]. In general, a smaller hyperbolic slope indicates a relatively greater number of particles in larger size classes. Furthermore, McCave [1975] and Bader [1970] point out that when $c=3$, the volume of particles remains equal in every log size increment. Thus, for slopes less than 3, the volume (and of course the mass) of particles in a given log size increment will increase with diameter. However, the slope cannot remain below 3 because the volume (mass) of suspended particles would be increasing with size, whereas large particles are much more likely to sink out of the hydrosol. Some have noted an increase in estimated slope beyond the value of 3 for particles greater than 4 to $10 \mu \mathrm{m}$ in diameter [Brun-Cottan, 1971; Jerlov, 1976]. Whichever slope is used, the hyperbolic models are simple estimates only which must be used with caution [Risovic, 2002; Jerlov, 1976; Kullenberg, 1974; McCave, 1975].

[12] Many investigators, however, accept the hyperbolic size distribution model as a first-order approximation to the actual size distribution of suspended marine particulates [Boss et al., 2001a, 2001b; Hammond et al., 1995; Forand and Fournier, 1999; Twardowski et al., 2001; Ulloa et al., 1994]. This assumption is often used in polydisperse Mie calculations to approximate the scattering coefficient of marine particulates. This was done by Schoonmaker et al. [1994] in discussing the optical environment of Oceanside, California. They assumed a hyperbolic size distribution for the sediment particles of California coastal waters and proposed that a hyperbolic $c$ coefficient of 2.1 was typical of coastal California waters and therefore of Oceanside, California. They arrived at this hypothesis by assuming a hyperbolic size distribution for an average of the total sediment particle load of California coastal waters and performing Mie calculations on these assumed particle distributions. The various Mie calculations were used to optimize the values of the hyperbolic slope coefficient to duplicate the total scattering coefficients that Petzold [1972] had published for San Diego Harbor and approximate the associated volume scattering functions (VSF). The $c$ value of 2.1 provided the best optimization to the Petzold data. No attempt was made to consider whether other particle size distributions fitted to the known total particle load, i.e., lognormal or gamma distributions [Jonasz and Fournier, 1996, 1999], would provide a suitable optimization to the Petzold results. As one approached shore, however, they proposed that the hyperbolic coefficient 2.1 would decrease as relatively more large particles would be suspended in the shallow coastal region.

[13] Schoonmaker et al. [1994] further investigated nearshore particle distributions in a field exercise at Oceanside, California, at a station approximately $20 \mathrm{~m}$ in depth. Scattering coefficients were measured directly by AC-9 instruments at various depth increments. A range of hyperbolic slopes was utilized for the total suspended particulate mass measured at each depth increment. Mie calculations were applied to each particle size distribution determined by a particular hyperbolic slope. A hyperbolic slope was assigned at each depth increment determined by the best fit of the Mie calculations to the measured scattering coefficient at that depth. This station corresponds most closely to either station ASM1 or station OM of the later 1995 Oceanside exercise (Figure 1). Estimates of the particle size range were made from samples collected at the field site, but they had been filtered and settled to remove larger particles. This treatment removes the most actively scattering particles and truncates the size range of suspended particles. With this size range and the estimated total sediment load, the optimum hyperbolic slope coefficients from Mie calculations for predicting the measured scattering coefficients were 1.9 at $2 \mathrm{~m}$ below the surface, 1.7 at $10 \mathrm{~m}$, and 1.3 near the bottom. This trend was explained by the effect of larger particles being resuspended as one approaches the bottom.

[14] A number of workers (see references above) are quite clear in stating that the hyperbolic slope model for the size distribution of suspended particulates is a first-order ap- 
Table 1. Data Collected During Littoral Optical Environment Exercise, Oceanside, California

\begin{tabular}{lccc}
\hline Observation & 19 October 1995 & 21 October 1995 & 24 October 1995 \\
\hline adcp & yes & yes & yes \\
chlorophyll & no & yes $^{\mathrm{a}}$ & yes \\
absorption & no & yes $^{\mathrm{a}}$ & yes $^{\mathrm{b}}$ \\
ac-9 & no & yes $^{\mathrm{a}}$ & yes $^{\mathrm{b}}$ \\
\hline
\end{tabular}

${ }^{\mathrm{a}}$ Station OM.

${ }^{\mathrm{b} S t a t i o n s}$ SCM2, OM, ASM1, OS6.

proximation only. Thus we are testing the assumption that hyperbolic slope models are an adequate approximation for suspended sediments in the nearshore region.

\section{Materials and Methods}

[15] Figure 1 shows the detailed latitude, longitude, and depths for the field site near Oceanside Harbor, California. The field exercise reported here was from the Littoral Optical Environment (LOE) Program of the Naval Research Laboratory and the Office of Naval Research. The optical mooring station, $\mathrm{OM}$, was the most frequently used for data collection. The labeled stations were a subsample of the total stations and are referred to as the optical line because they were the stations most frequently sampled optically. The dates of 21 and 24 October 1995 were chosen for analysis because of the availability of the most complete suites of optical, physical, chemical, and biological data (Table 1). Only one station, OM, was sampled on 21 October whereas all the stations in Figure 1 were sampled on 24 October. Minimal data were available for station OS6, but its proximity to stations with full data allows reasonable inferences to be drawn. The selected stations are representative of resuspension events occurring at shallow $(7 \mathrm{~m})$, mid-depth $(15 \mathrm{~m})$, and deep $(23 \mathrm{~m})$ stations. At stations of greater depth $(30+\mathrm{m})$ the resuspended sediment could be demonstrated in patterns similar to station OS6. Low particle numbers and lack of chlorophyll data for verification of total optical patterns reported here precluded inclusion of the deeper stations.

[16] The nearshore region is especially difficult to characterize for suspended minerogenic particulates because of the magnitude and variability of the forces influencing resuspension. Very large particles can be resuspended many times, and attempts to sample such particle distributions undoubtedly underestimate the concentration of larger particles. Because of these difficulties, there are few measurements of minerogenic particle size distributions in the nearshore region. Nevertheless, information on suspended mineral particulates is critical for formulating biogeo-optical models in coastal ocean systems.

[17] We are addressing this problem with a numerical sedimentation model TRANS98 [Keen and Slingerland, 1993; Keen and Glenn, 1998; Keen and Stavn, 2000], which consists of a wave-current interaction bottom boundary layer model (BBLM) derived from Glenn and Grant [1987] coupled to a sediment entrainment and transport model, and a bed conservation model. Input to the TRANS98 model consists of: (1) near-bottom steady current magnitude and direction; (2) wave orbital diameter, oscillatory current, and propagation direction; and (3) the
Table 2. Wave and Current Forcing at Station OM

\begin{tabular}{lcc}
\hline & 21 October & 24 October \\
\hline ADCP current & $0.092 \mathrm{~m} \mathrm{~s}^{-1}$ & $0.082 \mathrm{~m} \mathrm{~s}^{-1}$ \\
Significant wave height & $1.8 \mathrm{~m}$ & $1.35 \mathrm{~m}$ \\
Peak wave period & $6 \mathrm{~s}$ & $9 \mathrm{~s}$ \\
Wave orbital speed & $0.322 \mathrm{~m} \mathrm{~s}^{-1}$ & $0.41 \mathrm{~m} \mathrm{~s}^{-1}$ \\
Wave orbital diameter & $0.312 \mathrm{~m}$ & $0.627 \mathrm{~m}^{\circ}$ \\
Wave direction & $86^{\circ}$ & $89^{\circ}$ \\
\hline
\end{tabular}

sediment size distribution of the bottom. The bottom currents for this study are derived from the lowest vertical bin of ship-mounted ADCP data that were collected on cruises between 20 and 25 October 1995 at Oceanside, California (Tables 1 and 2). These currents are $1 \mathrm{~m}$ above the bottom. The entire set of measurements from one cruise, which lasted approximately 4 hours, are treated as a single timeaveraged field for this study. Wave orbital parameters were computed from the significant wave height and period measured by a bottom-mounted pressure gauge in a water depth of $10 \mathrm{~m}$ using linear wave theory. The wave direction was assumed the same as that measured at an offshore directional wave buoy (NOAA buoy 46045), because of the dominance of swell during the study interval. The resulting wave field was uniform over the study area but the bottom orbital parameters varied with water depth.

[18] Minerogenic sediments are typically represented by lognormal size distributions. Thus the $\varphi$-scale is used [Tanner, 1969]; $\varphi=-\log _{2}(d)$, where $d=$ particle diameter in $\mathrm{mm}$. The bottom sediment size distribution for water depths between 4 and $30 \mathrm{~m}$ at Oceanside has a mean of $3.2 \varphi$ $(110 \mu \mathrm{m})$ and a standard deviation of $0.5 \varphi$ [Inman, 1953]. This sediment is more than $99 \%$ quartz sand with a density of $2.650 \mathrm{~kg} / \mathrm{m}^{3}$. No bottom samples were collected during the fieldwork. The TRANS98 model uses sediment bins of $0.6 \varphi$ in this study. Thus the well-sorted sands at Oceanside are represented by five bins, with midpoints ranging from $4.3 \varphi(49.9 \mu \mathrm{m})$ to $2.1 \varphi(229 \mu \mathrm{m})$ (Figure 2). Figure 2 presents the particle size-weight percent plot for Oceanside that is standard in sedimentology and is what is reported by Inman [1953]. Prior to running the TRANS98 model, the

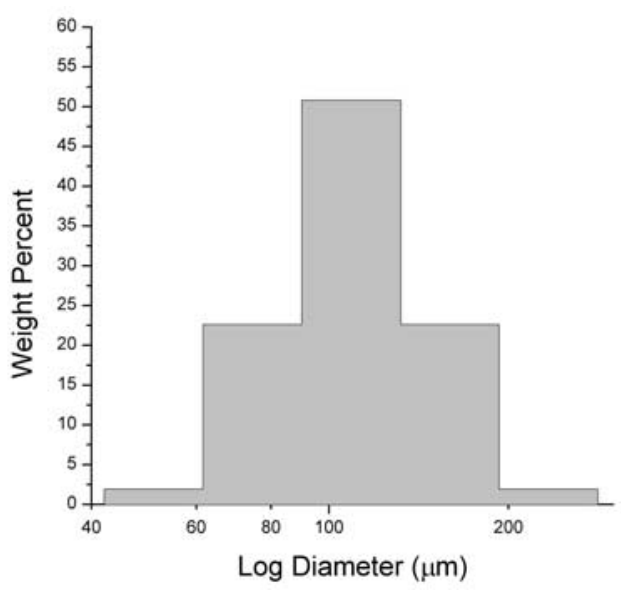

Figure 2. Histogram of sediment particle size classes and their weight percents, Oceanside, California. The weight percents converted to particle concentrations as explained in the text. 
weight-percent distribution in Figure 2 is converted to a mass concentration $\left(\mathrm{kg} / \mathrm{m}^{3}\right)$ for each size bin in a straightforward manner utilizing sediment density and porosity. Particle numbers are then computed using the median diameter for each size bin.

[19] The model calculates profiles of the bottom roughness, stability parameter, and size-fractionated suspended sediment. The BBLM is not sensitive to small variations in the viscosity of the water with temperature, but the modelpredicted sediment and optical profiles were examined for their sensitivity to the resuspension coefficient and the eddy diffusivity parameter, which is the ratio of the eddy diffusivity for sediment to the eddy viscosity (see Hill et al. [1988] for a discussion). These parameters are assigned values of 0.003 and 0.43 , respectively, as suggested by Styles [1998] for the New Jersey shelf, where the bottom sediment is similar to that in the study area. KS discuss the model sensitivity in more detail. The sedimentation model has a horizontal resolution of $200 \mathrm{~m}$. The TRANS98 model can be run as a resuspension model, which equates to an array of one-dimensional models like that of Glenn and Grant [1987] and Styles [1998]. The transport equations can also be used to calculate movement of sediment and changes in bed properties. For the study interval, sediment transport was minimal and there was no significant difference in the model results with transport calculated. The model results discussed below are interpolated to the optical stations in Figure 1.

[20] The sediment at Oceanside is predominantly quartz and a relative refractive index of 1.157 is used in polydisperse Mie scattering calculations [Bohren and Huffman, 1983; McCartney, 1976; Wiscombe, 1979]. The usual spherical approximation is applied. Even if the particles deviate from sphericity, the scattering calculations will yield an underestimate of the total scattering coefficient [Jonasz, 1986]. The wavelength of light used for all the calculations reported here is $532 \mathrm{~nm}$. The total scattering coefficient for mineral matter has only a slight variation with light wavelength [Bohren and Huffman, 1983; Shifrin, 1988], so we chose a wavelength in the middle of the visible spectrum that is utilized in many visibility studies [Weidemann et al., 1997]. Since all optical calculations are at one wavelength, the wavelength dependency is not expressed. The polydisperse Mie calculation is done as follows. For each size bin of the suspended sediment, we calculate the total scattering cross section $\left(\mathrm{m}^{2}\right)$ of each individual particle in the given size bin

$$
\sigma_{p}=2 \pi \int_{0}^{\pi} \sigma_{p}(\theta \sin \theta d \theta)
$$

where $\sigma_{p}$ is the total scattering cross section for a single particle. The standard Mie calculation is performed with the mid-point of the size bin taken as the mean diameter of the particles in that bin. The Mie calculation gives the differential scattering cross section of the particle at angle $\theta$, $\sigma_{p}(\theta)$, the projected area of the particle at that angle. The integration in equation (3) then gives the total scattering cross section, which is a measure of the power per unit area removed or diverted from the light irradiance encountering the particle [McCartney, 1976; Jonasz, 1991]. We then determine the efficiency factor, which is the ratio of the total scattering cross section to the projected cross sectional area of a particle.

$$
Q_{s c}=\frac{\sigma_{p}}{\pi r^{2}}
$$

where $Q_{s c}$ is the efficiency factor and $r$ is the radius of the particle. We then determine the total scattering coefficient for minerogenic particles of a given radius $r_{i}$ from

$$
\mathrm{b}_{m i}=N_{i} \sigma_{p i}=N_{i} \pi r_{i}^{2} Q_{s c i}
$$

where $\mathrm{b}_{m i}$ is the total scattering coefficient and $N_{i}$ is the concentration of particles per $\mathrm{m}^{3}$ of radius $r_{i}$. The total scattering coefficient is a measure of the light power removed or diverted by a unit volume of the scattering medium. When we have several size classes subscripted with $i$,

$$
b_{m}=\sum_{i} N_{i} \pi r_{i}^{2} Q_{s c i}
$$

where $b_{m}$ is the scattering coefficient of the entire ensemble of mineral particles of all sizes suspended in a unit volume of the medium.

[21] The total suspended loads predicted by TRANS98 at specified depths within the water column are substituted for $N$ in equation (1), and hyperbolic slope models of the particle size distributions are constructed. These computations are only made at stations where the following criteria are met: (1) chlorophyll data were collected, making it possible to apply the biogeo-optical model of $\mathrm{KS}$; and (2) the water depths are small enough for surface waves to have an influence on bottom stresses. Thus the results do not include the impact of internal waves on sediment resuspension in deeper water. We chose hyperbolic slope coefficients of $2.7,2.1,1.8,1.3$, and 1.0, which bracket the limits proposed by Schoonmaker et al. [1994] for the Oceanside area. Hyperbolic slope models are then generated for several depths at each station on 21 and 24 October using equation (1), and substituting the values given above into $c$. Out of the several depths utilized in the TRANS98 model, we chose the depths of $0.14-0.30 \mathrm{~m}$ off the bottom, $2 \mathrm{~m}$ off the bottom, and at the ocean surface for each station. The region near $0.14 \mathrm{~m}$ is lying in the bottom boundary layer for each station, the $2 \mathrm{~m}$ depth is just above the bottom boundary layer, and the surface values give an indication of how the dynamics of mineral resuspension might affect the remote sensing signal from the mineral backscattering coefficient.

[22] The hyperbolic slope models are compared with the TRANS98 results for particle size concentrations in individual size bins (Figures 3-7) and for the total scattering coefficient determined from the polydisperse Mie calculation for each model (Tables 3 and 4). We also consider the backscattering coefficients at the water surface $\left(0^{-} \mathrm{m}\right.$ depth) in consideration of possible effects on remote sensing algorithms (Table 5). Finally, we compare the TRANS98 and hyperbolic slope model total (minerogenic) scattering coefficients with calculations of the minerogenic scattering coefficient utilizing the KS biogeo-optical model (Table 6). The KS biogeo-optical mineral estimates are 

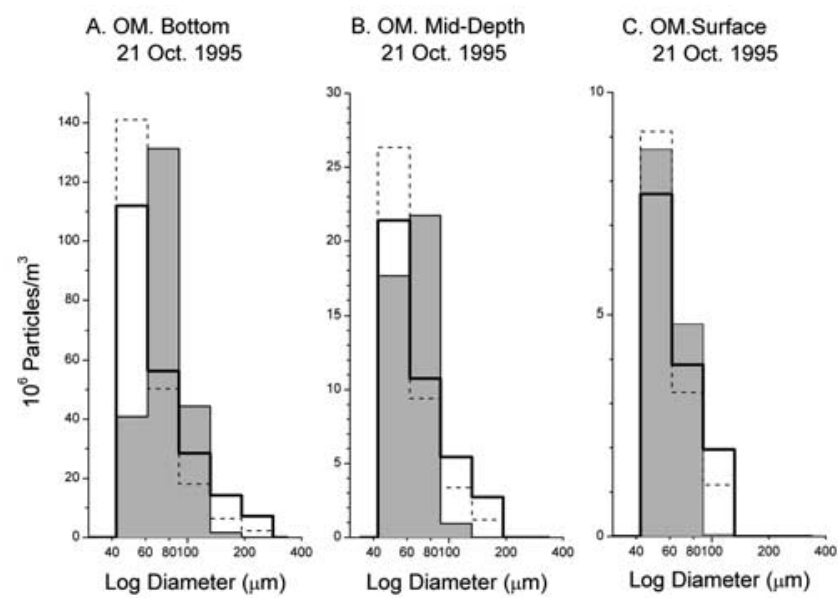

Figure 3. Histograms of particle size concentrations at Station OM, 21 October 1995, generated by TRANS98 compared with the concentrations predicted from hyperbolic slope model for $\mathrm{c}=1.8$ and $\mathrm{c}=2.7$ at (a) $0.14 \mathrm{~m}$ above bottom, (b) $2.25 \mathrm{~m}$ above bottom, and (c) water surface, $15.4 \mathrm{~m}$ above bottom.

now summarized. The KS estimate of mineral scattering utilizes the AC-9 scattering coefficients, the size-partitioned chlorophyll concentrations, and partitioned absorption coefficients reported for the LOE Oceanside exercise [Roesler, 1995]. The total scattering coefficient at the stations chosen comes from the AC-9 data. There is a small error associated with this instrument. We determine the scattering coefficient for the organic matter from the chlorophyll concentration. Two optical scattering cross sections are used for algae to obtain the scattering coefficient attributable to algal cells. This is based on the theoretical development by Morel [1987] in which he determined that the optical scattering cross section assumes a relatively large value for algal cells smaller than $10 \mu \mathrm{m}$ diameter and a smaller value for cells
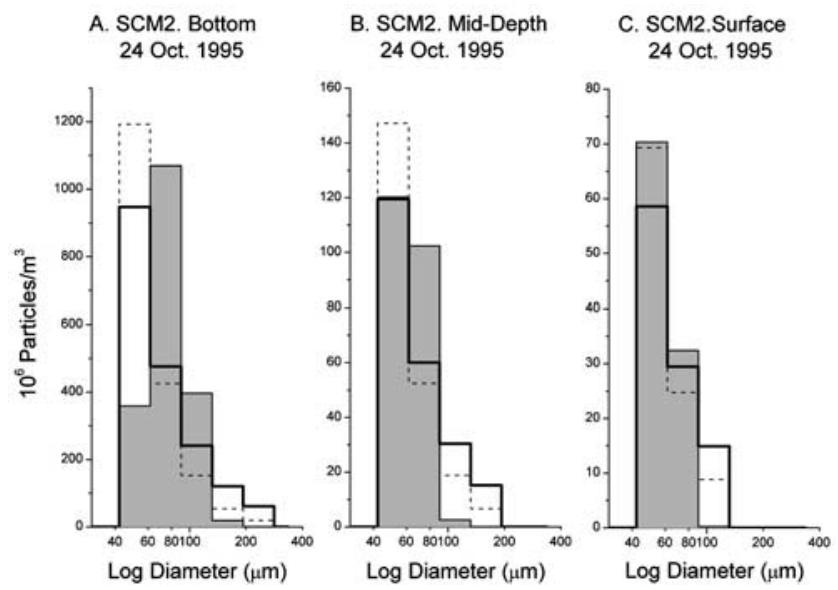

Figure 4. Histograms of particle size concentrations at Station SCM2, 24 October 1995, generated by TRANS98 compared with the concentrations predicted from hyperbolic slope model for $\mathrm{c}=1.8$ and $\mathrm{c}=2.7$ at (a) $0.13 \mathrm{~m}$ above bottom, (b) $2.34 \mathrm{~m}$ above bottom, and (c) water surface, $8.9 \mathrm{~m}$ above bottom.

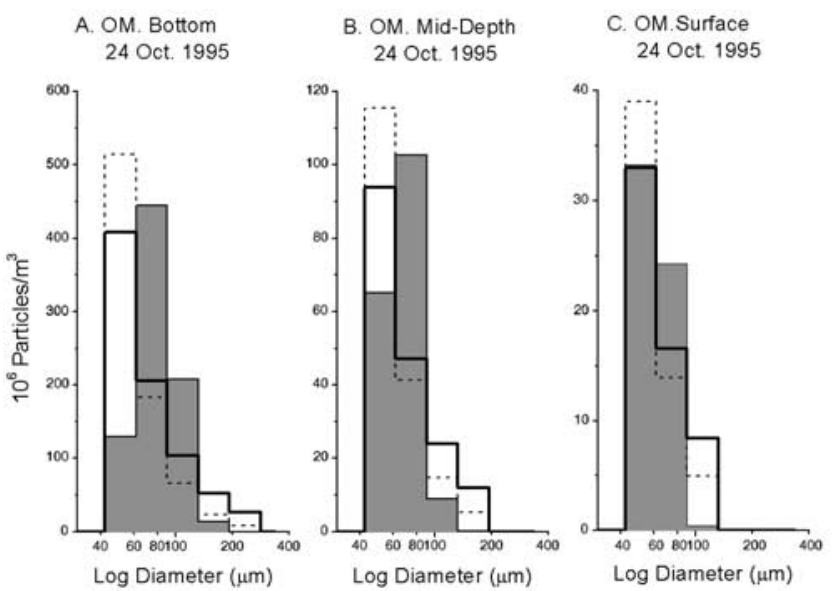

Figure 5. Histograms of particle size concentrations at Station OM, 24 October 1995, generated by TRANS98 compared with the concentrations predicted from hyperbolic slope model for $\mathrm{c}=1.8$ and $\mathrm{c}=2.7$ at (a) $0.16 \mathrm{~m}$ above bottom, (b) $2.04 \mathrm{~m}$ above bottom, and (c) water surface, $15.5 \mathrm{~m}$ above bottom.

greater than $10 \mu \mathrm{m}$ diameter. We were able to apply his theoretical conclusion because many of the chlorophyll concentrations at the moorings were reported for several size fractions filtered from the water samples. Optical scattering cross sections for several marine phytoplankton species were obtained from Ahn et al. [1992] and Bricaud et al. [1988], and averages were obtained for cells less than $10 \mu \mathrm{m}$ diameter and for those greater than $10 \mu \mathrm{m}$ diameter. Standard deviations were then determined for the two groups. Scattering due to bacteria was estimated from bacterial numbers reported for the southern California bight [Cho and Azam, 1990] and from a chlorophyll bacterial-number relation of Cole et al. [1988]. The numbers were converted to scattering coefficients from a scattering efficiency factor
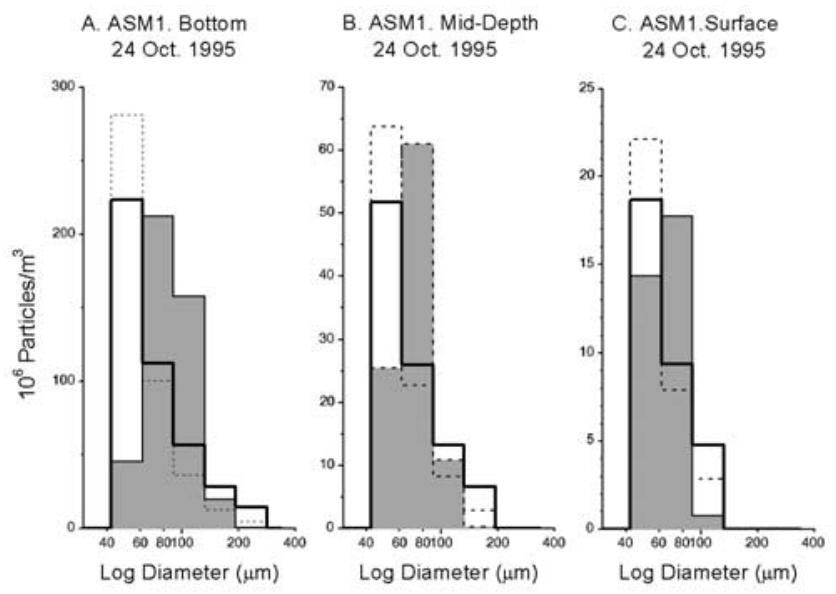

Figure 6. Histograms of particle size concentrations Station ASM1, 24 October 1995, generated by TRANS98 compared with the concentrations predicted from hyperbolic slope model for $\mathrm{c}=1.8$ at (a) $0.14 \mathrm{~m}$ above bottom, (b) $2.50 \mathrm{~m}$ above bottom, and (c) water surface, $20.8 \mathrm{~m}$ above bottom. 


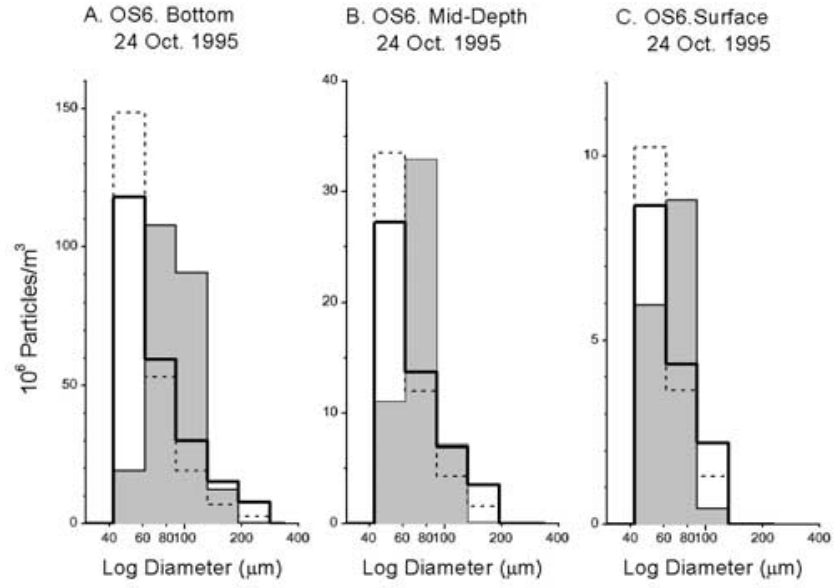

Figure 7. Histograms of particle size concentrations Station OS6, 24 October 1995, generated by TRANS98 compared with the concentrations predicted from hyperbolic slope model for $\mathrm{c}=1.8$ and $\mathrm{c}=2.7$ at (a) $0.14 \mathrm{~m}$ above bottom, (b) $2.07 \mathrm{~m}$ above bottom, and (c) water surface, $23 \mathrm{~m}$ above bottom.

determined by Morel and Ahn [1990] and Stramski and Kiefer [1990]. Standard deviations were determined for the bacterial numbers and applied to the bacterial scattering coefficient estimates. Organic detritus scattering was determined from differencing bacterial and algal scattering with total organic scattering from Loisel and Morel [1998]. We used the error estimates of Loisel and Morel [1998]. The difference between the AC-9 scattering coefficient and the organic scattering coefficient (the sum of algal, bacterial, and organic detrital scattering) then becomes the estimate of suspended mineral scattering of the biogeo-optical model of KS. The standard deviations determined for all components of the mineral scattering estimate were then mathematically propagated as described by Taylor [1982] to obtain the probable error in the estimation of the mineral scattering coefficient. These probable errors are reported in Table 6.

\section{Results}

[23] The physical-optical sedimentation model (TRANS98) predicts suspended sediment profiles that are dependent on the physical environment at the bottom and the distribution of sediment particle sizes in the bed (Figure 2). Plots of the predicted suspended particle distributions are given for selected stations at $0.14-$ $0.30 \mathrm{~m}$ off the bottom, $2 \mathrm{~m}$ off the bottom, and at the ocean surface (Figures $3-7$ ). These plots illustrate the size distributions predicted from the total suspended particle concentrations of TRANS98 as well as the results obtained from hyperbolic slope models of 2.7 and 1.8. These slopes were selected to illustrate the trends in particle size distribution represented by the hyperbolic slope models proposed for the Oceanside site. Hyperbolic slope 2.7 covers the extreme upper range of slopes proposed for Oceanside while slope 1.8 is in the upper to middle range for the slopes proposed for this site. The incident waves on October 21 (Table 2) had a height of $1.8 \mathrm{~m}$ and a period of $6 \mathrm{~s}$. This wave field was assumed uniform over the small study area (Figure 1). However, because of variations in water depth at the different stations, there are significant differences in the wave bottom orbital parameters. The currents are interpolated from the ship-based ADCP measurements and are thus spatially variable. However, because of the weak oceanographic conditions during the study interval, the steady currents are relatively uniform. For the water depth at station OM $(15.5 \mathrm{~m})$, the resulting wave orbital velocity is $0.32 \mathrm{~m} \mathrm{~s}^{-1}$ and the orbital diameter is $0.31 \mathrm{~m}$. The ADCP currents at this station were $0.092 \mathrm{~m} \mathrm{~s}^{-1}$. Thus the bottom boundary layer was wavedominated at station OM. The wave field shifted towards ocean swell on 24 October; the wave height decreased to $1.35 \mathrm{~m}$ but the period increased to $9 \mathrm{~s}$. The resulting bottom wave orbital velocity and diameter at station OM increased to $0.41 \mathrm{~m} \mathrm{~s}^{-1}$ and $0.62 \mathrm{~m}$, respectively, while the bottom currents decreased slightly to $0.082 \mathrm{~m} \mathrm{~s}^{-1}$.

[24] Because of the weak physical forcing on 21 October, the concentration of particles predicted by TRANS98 (shaded histogram) at station OM (the only station on this date) was low (Figure 3) compared with the same station on 24 October (Figure 5). This is easily demonstrated near the bottom where the modal size class $(73 \mu \mathrm{m})$ has a concentration of $131.2 \times 10^{6}$ particles $/ \mathrm{m}^{3}$ (Figure 3a) whereas the same station on 24 October has a modal size class $(73 \mu \mathrm{m})$ concentration of $445 \times 10^{6}$ particles $/ \mathrm{m}^{3}$ (Figure $5 \mathrm{a}$ ), a factor of about 3.4 increase. This dramatic increase in suspension is caused by the shift to fair-weather swell rather than storm waves. The pattern of concentration differences between the two dates persists from the bottom to the surface.

\subsection{Numerical Model Particle Distributions}

\subsubsection{October 1995}

[25] At station OM, the distribution of suspended size classes (shaded) near the bottom (Figure 3a) appears to be Gaussian lognormal with the concentrations skewed toward the smaller size classes. At $2.24 \mathrm{~m}$ above the bottom (Figure $3 \mathrm{~b}$ ), the relative distribution of particle concentrations shifts as larger particles tend to settle out and the smallest size class becomes more important. At the surface the $50-\mu \mathrm{m}$ size class clearly dominates as the largest size classes have disappeared (Figure 3c).

\subsubsection{October 1995}

[26] The overall size distribution patterns on 24 October are similar for stations SCM2 and OM (compare Figures 4 and 5). Near the bottom, these stations exhibit a modal size

Table 3. Total Scattering Coefficients for Suspended Mineral Matter, Oceanside, California, 21 October 1995, 2030 UT, Station OM

\begin{tabular}{|c|c|c|c|c|c|c|c|}
\hline & $\begin{array}{c}\text { Distance Above } \\
\text { Bottom, m }\end{array}$ & $\begin{array}{c}\text { Trans 98, } \\
b_{m} m^{-1} \\
\end{array}$ & $\begin{array}{l}\text { Hyperbolic Slope } \\
1.0, \mathrm{~b}_{\mathrm{m}} \mathrm{m}^{-1}\end{array}$ & $\begin{array}{l}\text { Hyperbolic Slope } \\
1.3, \mathrm{~b}_{\mathrm{m}} \mathrm{m}^{-1}\end{array}$ & $\begin{array}{l}\text { Hyperbolic Slope } \\
1.8, \mathrm{~b}_{\mathrm{m}} \mathrm{m}^{-1}\end{array}$ & $\begin{array}{l}\text { Hyperbolic Slope } \\
2.1, \mathrm{~b}_{\mathrm{m}} \mathrm{m}^{-1}\end{array}$ & $\begin{array}{c}\text { Hyperbolic Slope } \\
2.7, \mathrm{~b}_{\mathrm{m}} \mathrm{m}^{-1} \\
\end{array}$ \\
\hline Surface & 15.5 & 0.08 & 0.12 & 0.11 & 0.1 & 0.09 & 0.09 \\
\hline Mid & 2.24 & 0.27 & 0.5 & 0.45 & 0.38 & 0.35 & 0.29 \\
\hline Bottom & 0.14 & 2.15 & 3.97 & 3.37 & 2.6 & 2.26 & 1.77 \\
\hline
\end{tabular}


Table 4. Total Scattering Coefficients for Suspended Mineral Matter, Oceanside, California, 24 October 1995, 0825 UT

\begin{tabular}{|c|c|c|c|c|c|c|c|}
\hline & $\begin{array}{c}\text { Distance Above } \\
\text { Bottom, m }\end{array}$ & $\begin{array}{c}\text { Trans } 98, \\
b_{m} m^{-1}\end{array}$ & $\begin{array}{l}\text { Hyperbolic Slope } \\
1.0, \mathrm{~b}_{\mathrm{m}} \mathrm{m}^{-1}\end{array}$ & $\begin{array}{l}\text { Hyperbolic Slope } \\
1.3, \mathrm{~b}_{\mathrm{m}} \mathrm{m}^{-1}\end{array}$ & $\begin{array}{l}\text { Hyperbolic Slope } \\
1.8, \mathrm{~b}_{\mathrm{m}} \mathrm{m}^{-1}\end{array}$ & $\begin{array}{l}\text { Hyperbolic Slope } \\
2.1, \mathrm{~b}_{\mathrm{m}} \mathrm{m}^{-1}\end{array}$ & $\begin{array}{l}\text { Hyperbolic Slope } \\
2.7, \mathrm{~b}_{\mathrm{m}} \mathrm{m}^{-1}\end{array}$ \\
\hline \multicolumn{8}{|c|}{ Station $O M$} \\
\hline Surface & 15.5 & 0.35 & 0.49 & 0.47 & 0.43 & 0.41 & 0.37 \\
\hline Mid & 2.03 & 1.3 & 2.2 & 1.98 & 1.68 & 1.53 & 1.29 \\
\hline Bottom & 0.16 & 8.61 & 14.46 & 12.29 & 9.49 & 8.23 & 6.45 \\
\hline \multicolumn{8}{|c|}{ Station ASM1 } \\
\hline Surface & 20.08 & 0.22 & 0.41 & 0.37 & 0.31 & 0.28 & 0.24 \\
\hline Mid & 2.50 & 0.83 & 1.21 & 1.09 & 0.93 & 0.84 & 0.71 \\
\hline Bottom & 0.14 & 5.63 & 7.92 & 6.73 & 5.2 & 4.51 & 3.53 \\
\hline
\end{tabular}

class of $73 \mu \mathrm{m}$ with the $107-\mu \mathrm{m}$ class being next most prevalent (Figures $4 \mathrm{a}$ and 5a). At approximately $2 \mathrm{~m}$ above the bottom (Figures $4 \mathrm{~b}$ and $5 \mathrm{~b}$ ) the modal size class switches to $50 \mu \mathrm{m}$ for the shallower SCM2 station while it remains at $73 \mu \mathrm{m}$ for the deeper OM station. Finally, at the surface, the dominant size class becomes $50 \mu \mathrm{m}$ for both stations (Figures $4 \mathrm{c}$ and $5 \mathrm{c}$ ).

[27] At the deeper stations (ASM1 and OS6), the modal size class remains $73 \mu \mathrm{m}$ throughout the water column, but the second largest concentration shifts from coarser to finer sediment. The second greatest concentration is in the $107-\mu \mathrm{m}$ class near the bed (Figures 6a and 7a). At approximately $2 \mathrm{~m}$ above the bottom, the next largest concentration is in the $50-\mu \mathrm{m}$ class (Figures $6 \mathrm{~b}$ and $7 \mathrm{~b}$ ), which becomes comparable to the mode near the surface (Figures $6 \mathrm{c}$ and $7 \mathrm{c}$ ).

\subsection{Hyperbolic Slope Model Particle Distributions}

[28] Each histogram in Figures 3-7 contains a particle size distribution (open solid line) determined from the hyperbolic slope 1.8 model via equation (1), a particle size distribution (open dotted line) determined from the hyperbolic slope 2.7 model via equation (1), and the total particle concentrations determined from TRANS98 (shaded) at each station.

\subsubsection{October 1995}

\subsubsection{Slope 1.8}

[29] At the bottom at station OM (the only station on this date) the hyperbolic slope model overestimates the $50-\mu \mathrm{m}$ size class by a factor of 2.8 (Figure $3 a$ ) whereas the 73 - and $107-\mu \mathrm{m}$ size classes are underestimated. The largest size classes $(157$ and $229 \mu \mathrm{m})$ are overestimated by a factor of 8.6 and multiple orders of magnitude, respectively. At $2.24 \mathrm{~m}$ above the bottom (Figure $3 \mathrm{~b}$ ), the smallest and largest size classes are again overestimated whereas the middle size classes are underestimated; the $50-\mu \mathrm{m}$ size class is overestimated by $20 \%$, the $107-\mu \mathrm{m}$ size class is underestimated by a factor of 0.49 , and the largest size classes are overestimated by a factor of 5.8 and multiple orders of magnitude, respectively. At the water surface (Figure 3c) the trend changes, with the smallest and middle size classes underestimated and the largest size class overestimated by 5.4 orders of magnitude.

\subsubsection{Slope 2.7}

[30] At station OM the hyperbolic slope model overestimates the $50-\mu \mathrm{m}$ size class at the bottom by a factor of 3.5 (Figure $3 \mathrm{a}$ ). The next two size classes are underestimated whereas the 157- and 229- $\mu \mathrm{m}$ size classes are significantly overestimated. At $2.24 \mathrm{~m}$ above the bottom (Figure $3 \mathrm{~b}$ ), the trend noted near the bottom continues; the $50-\mu \mathrm{m}$ size class is overestimated by $50 \%$, the middle size class is underestimated by a factor of 0.44 , and the next larger size classes are overestimated. At the water surface (Figure 3c), the smallest size class is overestimated by $5 \%$ and the middle size class underestimated by a factor of 0.67 . The largest size class is greatly overestimated.

\subsubsection{October 1995}

\subsubsection{Slope 1.8}

[31] At the bottom at station SCM2 (the shallowest station) the hyperbolic slope model overestimates the $50-\mu \mathrm{m}$ class by a factor of 2.7 (Figure $4 \mathrm{a}$ ). The next size class is significantly underestimated whereas the $107-\mu \mathrm{m}$ class is overestimated by a factor of 1.7 , and the 157- and $229-\mu \mathrm{m}$ size classes are substantially overestimated. At $2.34 \mathrm{~m}$ above the bed (Figure 4b), the smallest size class is slightly underestimated, the $73-\mu \mathrm{m}$ class is underestimated by a factor of 0.57 , and the 107 - and $157-\mu \mathrm{m}$ size classes are overestimated by orders of magnitude. At the water surface (Figure $4 \mathrm{c}$ ), the 50 - and $73-\mu \mathrm{m}$ classes are underestimated by less than $20 \%$, whereas the $107-\mu \mathrm{m}$ size class is overestimated by many orders of magnitude.

[32] At station OM (depth $=15.5 \mathrm{~m})$ the hyperbolic slope model overestimates the $50-\mu \mathrm{m}$ size class by a factor of 3.2 (Figure 5a) at the bottom whereas the 73- and $107-\mu \mathrm{m}$

Table 5. Backscattering Coefficients $\left(b_{b m} m^{-1}\right)$ of Suspended Minerogenic Matter at Surface, Oceanside, California: Comparison With Hyperbolic Slope Models ${ }^{\mathrm{a}}$

\begin{tabular}{|c|c|c|}
\hline \multicolumn{2}{|l|}{21 October 1995} & 24 October 1995 \\
\hline \multicolumn{3}{|c|}{ Station $O M$} \\
\hline 0.0013 & & 0.0059 \\
\hline $0.0014(2.7)$ & & $0.0062(2.7)$ \\
\hline $0.0016(2.1)$ & & $0.0068(2.1)$ \\
\hline $0.0017(1.8)$ & & $0.0071(1.8)$ \\
\hline $0.0018(1.3)$ & & $0.0078(1.3)$ \\
\hline $0.0019(1.0)$ & & $0.0082(1.0)$ \\
\hline \multicolumn{3}{|c|}{ Station ASMI } \\
\hline & & 0.0038 \\
\hline & & $0.0040(2.7)$ \\
\hline & & $0.0048(2.1)$ \\
\hline & & $0.0052(1.8)$ \\
\hline & & 0.0061 (1.3) \\
\hline & & $0.0067(1.0)$ \\
\hline
\end{tabular}

${ }^{a}$ Backscattering values from hyperbolic slope models with their hyperbolic slope following in parentheses. Hyperbolic slopes unlikely to be found in surface layers but proposed for those layers are listed in italic. Backscattering values from TRANS98 are in boldface. 
Table 6. In Situ and Predicted Total Scattering Coefficients for Suspended Mineral Matter, Oceanside, California

\begin{tabular}{|c|c|c|c|c|c|c|c|c|}
\hline & $\begin{array}{c}\text { Distance Above } \\
\text { Bottom, m }\end{array}$ & $\begin{array}{c}\text { Optical } \\
\text { Observation, } \\
\mathbf{b}_{\mathbf{m}} \mathbf{m}^{-1} \\
\end{array}$ & $\begin{array}{c}\text { Trans 98, } \\
\mathbf{b}_{\mathrm{m}} \mathbf{m}^{-1}\end{array}$ & $\begin{array}{c}\text { Hyperbolic } \\
\text { Slope } 1.0 \\
b_{\mathrm{m}} \mathrm{m}^{-1}\end{array}$ & $\begin{array}{c}\text { Hyperbolic } \\
\text { Slope } 1.3, \\
\mathrm{~b}_{\mathrm{m}} \mathrm{m}^{-1}\end{array}$ & $\begin{array}{c}\text { Hyperbolic } \\
\text { Slope } 1.8 \\
\mathrm{~b}_{\mathrm{m}} \mathrm{m}^{-1}\end{array}$ & $\begin{array}{c}\text { Hyperbolic } \\
\text { Slope } 2.1, \\
\mathrm{~b}_{\mathrm{m}} \mathrm{m}^{-1}\end{array}$ & $\begin{array}{c}\text { Hyperbolic } \\
\text { Slope } 2.7, \\
b_{m} m^{-1} \\
\end{array}$ \\
\hline \multicolumn{9}{|c|}{ Station OM, 21 October 1995, 2030 UT } \\
\hline Surface & 11.76 & $\mathbf{0 . 0 8 9} \pm \mathbf{0 . 1 2 7}$ & 0.09 & 0.14 & 0.13 & 0.12 & 0.11 & 0.09 \\
\hline Bottom (Near) & 6.60 & $0.16 \pm 0.11$ & 0.14 & 0.19 & 0.18 & 0.17 & 0.16 & 0.14 \\
\hline \multicolumn{9}{|c|}{ Station OM, 24 October 1995, 0825 UT } \\
\hline Surface & 15.50 & $0.34 \pm 0.09$ & 0.35 & 0.49 & 0.47 & 0.43 & 0.41 & 0.37 \\
\hline Bottom (near) & 6.50 & $0.57 \pm 0.17$ & 0.64 & 0.2 & 1.08 & 0.92 & 0.83 & 0.71 \\
\hline \multicolumn{9}{|c|}{ Station ASM1, 24 October 1995, 0825 UT } \\
\hline Mid & 11.80 & $\mathbf{0 . 3 2} \pm \mathbf{0 . 0 4 3}$ & 0.33 & 0.56 & 0.51 & 0.43 & 0.39 & 0.33 \\
\hline \multicolumn{9}{|c|}{ Station SCM2, 24 October 1995, 0825 UT } \\
\hline Surface (near) & 7.10 & $0.63 \pm 0.069$ & 0.66 & 1.00 & 0.95 & 0.87 & 0.82 & 0.75 \\
\hline
\end{tabular}

classes are underestimated. The 157- and 229- $\mu$ m classes are overestimated by many orders of magnitude. At $2.04 \mathrm{~m}$ above the bottom (Figure $5 \mathrm{~b}$ ), the near-bottom trend of overestimating the smallest and largest size classes while underestimating the middle size class continues. The $50-\mu \mathrm{m}$ size class is overestimated by $40 \%$, the $73-\mu \mathrm{m}$ class is underestimated by a factor of 0.46 , and the largest size classes in suspension are overestimated by factors of 2.7 and 26, respectively. At the water surface (Figure 5c) the trend changes, with the smallest size class slightly underestimated, the $73-\mu \mathrm{m}$ class overestimated by $50 \%$, and the largest size class greatly overestimated.

[33] At station ASM1 (depth = $20 \mathrm{~m}$ ) the hyperbolic slope model overestimates the $50-\mu \mathrm{m}$ class by a factor of 4.8 (Figure 6a) at the bottom whereas the 73- and $107-\mu \mathrm{m}$ classes are underestimated. The 157- and 229- $\mu \mathrm{m}$ size classes are overestimated by several orders of magnitude. At $2.42 \mathrm{~m}$ above the bottom (Figure $6 \mathrm{~b}$ ), the trend noted near the bottom of overestimating the smallest and largest size classes while underestimating the middle size class continues. The $50-\mu \mathrm{m}$ class is overestimated by a factor of 2.1 , the $73-\mu \mathrm{m}$ class is underestimated by a factor of 0.42 , and the largest size classes are overestimated by orders of magnitude. This trend continues at the water surface (Figure 6c), with the smallest size class overestimated by $30 \%$, the $73-\mu \mathrm{m}$ class underestimated by a factor of 0.53 , and the largest size class in suspension overestimated by a factor of 6 .

[34] At the bottom at station OS6 (the deepest station investigated here) the hyperbolic slope model overestimates the $50-\mu \mathrm{m}$ size class by a factor of 6.2 (Figure 7a), but the $73-$ and $107-\mu \mathrm{m}$ size classes are underestimated. The 157and $229-\mu \mathrm{m}$ classes are overestimated by $28 \%$ and several orders of magnitude, respectively. At $1.9 \mathrm{~m}$ above the bed (Figure $7 \mathrm{~b}$ ), the trend noted near the bottom continues; the smallest size class is overestimated by a factor of 2.4 , the next larger size class is underestimated by a factor of 0.41 and the $107-\mu \mathrm{m}$ class is slightly underestimated. The largest size class is overestimated by several orders of magnitude. The trend continues at the water surface (Figure 7c).

\subsubsection{Slope 2.7}

[35] At station SCM2 (the shallowest station), the hyperbolic slope model (dashed line) overestimates the $50-\mu \mathrm{m}$ size class by a factor of 3.3 (Figure $4 \mathrm{a}$ ) at the bottom. The
73- and $107-\mu \mathrm{m}$ classes are significantly underestimated but the largest size classes are greatly overestimated. At $2.34 \mathrm{~m}$ above the bottom (Figure $4 \mathrm{~b}$ ) this trend continues; the smallest size class is overestimated by $20 \%$, the $73-\mu \mathrm{m}$ class is underestimated by a factor of 0.51 , and the largest size classes are again overestimated by orders of magnitude. The trend changes at the water surface (Figure 4c), with the 50- and $73-\mu \mathrm{m}$ classes being underestimated and the $107-\mu \mathrm{m}$ class greatly overestimated.

[36] At the bottom at station OM (depth $=15.5 \mathrm{~m})$ the hyperbolic slope model overestimates the smallest size class by a factor of 4.0 (Figure 5a), but the next two size classes are underestimated. The largest size classes (157 and $229 \mu \mathrm{m})$ are substantially overestimated. This trend continues at $2.04 \mathrm{~m}$ above the bottom (Figure $5 \mathrm{~b}$ ). The smallest size class is overestimated by a factor of 1.8 , the $73-\mu \mathrm{m}$ class is underestimated by a factor of 0.39 , and the largest size classes are again overestimated by orders of magnitude. The trend continues at the water surface (Figure $5 \mathrm{c}$ ).

[37] At station ASM1 (depth = $20 \mathrm{~m})$ the hyperbolic slope model overestimates the smallest size class by a factor of 6.4 at the bottom (Figure 6a). The 73- and 107- $\mu \mathrm{m}$ classes are significantly underestimated. The 157- and 229- $\mu \mathrm{m}$ classes are overestimated by about 1.5 orders of magnitude. At mid-depth (Figure 6b), the $50-\mu \mathrm{m}$ class is overestimated by a factor of 2.5 , the $73-\mu \mathrm{m}$ size class is underestimated by a factor of 0.37 , and the largest size classes are overestimated by $33 \%$ and 1.9 orders of magnitude, respectively. At the water surface (Figure $6 \mathrm{c}$ ) the $50-\mu \mathrm{m}$ size class is overestimated by a factor of $60 \%$. The middle size class is underestimated by a factor of 0.44 and the largest size class is overestimated by a factor of 3.6.

[38] At station OS6 (the deepest station investigated here), the hyperbolic slope model overestimates the smallest size class by a factor of 8 at the bottom (Figure 7a) but the $73-\mu \mathrm{m}$ and the $100-\mu \mathrm{m}$ size classes are significantly underestimated. The $107-\mu \mathrm{m}$ size class is underestimated by $50 \%$ whereas the $156-\mu \mathrm{m}$ class is overestimated by more than an order of magnitude. At mid-depth (Figure 7b), the near-bottom trend continues. The smallest size class is overestimated by a factor of 3.0 , the $73-\mu \mathrm{m}$ size class is underestimated by a factor of 0.36 , the $107-\mu \mathrm{m}$ size class is underestimated by a factor of 0.58 , and the largest size class in suspension is overestimated by 1.2 orders of 
magnitude. At the water surface (Figure 7c) the trend continues, with the smallest size class overestimated, the middle size class underestimated, and the largest size class overestimated by a factor of 3 .

\subsection{Minerogenic Scattering Coefficients}

[39] Minerogenic scattering coefficients for stations OM and ASM1 are given in Tables 3 and 4 for immediately above the bottom, about $2 \mathrm{~m}$ above the bottom, and at the ocean surface, and can be compared directly with the plots in Figures 3, 5, and 6. These stations were chosen to correspond to the area and the approximate depth sampled by Schoonmaker et al. [1994] to estimate the hyperbolic slopes proposed for the California coast. The scattering coefficients are computed from the particle size distributions calculated by the TRANS98 sedimentation model and the hyperbolic slope models using equations (3)-(6). The TRANS98 coefficients (indicated by boldface) are compared with five hyperbolic slope models that bracket the slopes proposed by Schoonmaker et al. [1994]. At each comparison depth in Tables 3 and 4, the scattering coefficient determined from the hyperbolic slope model predicted by Schoonmaker et al. [1994] for that depth is indicated by italics.

[40] The hyperbolic model results, for the most part, overestimate the scattering coefficients determined from the sedimentation model results for the cases discussed by Schoonmaker et al. [1994]. Near the bottom, the hyperbolic slope 1.3 model deviates from the baseline by $20 \%$ to $57 \%$. At $2 \mathrm{~m}$ above the bottom, the hyperbolic slope model 1.8 deviates from the baseline by $12 \%$ to $40 \%$. The deviations of slope model 2.1 from the TRANS98 baseline are between $13 \%$ and $27 \%$ at the surface. The overall best-fitting hyperbolic slope model has a slope of 2.7 , with deviations at all depths that range from $1 \%$ to $14 \%$, except for an outlier of $37 \%$.

[41] The computed minerogenic backscatter coefficients near the surface at stations OM and ASM1 are given in Table 5. The minerogenic backscatter coefficients calculated from the TRANS98 baseline (boldface) are compared with the five hyperbolic slope models. In the surface layer, the hyperbolic slope models always overestimate the backscatter coefficient. The best estimate comes from slope model 2.7 , however, where the overestimation ranges from $5 \%$ to $8 \%$. For the hyperbolic slope models in the range of 2.1 to 1.8 , the deviations range from $15 \%$ to $37 \%$.

[42] Minerogenic total scatter coefficients derived from the optical and chemical data recorded from the stations we investigated are in Table 6, along with their range of probable error. These coefficients were obtained by difference from AC-9 scattering coefficients and the organic scatter coefficients determined from the chlorophyll concentration and the absorption coefficient partitioning (KS) at the stations in question. Before this comparison was made, the chlorophyll data were screened for possible interaction of the instrument with the bottom, and only uncontaminated data were used. We interpolated the TRANS98 results and the hyperbolic slope model results to correspond with the depths at the stations where the optical and chemical data were collected. The TRANS98 results deviated from the biogeo-optical determinations by $3 \%$ to $5 \%$ with an outlier at $14 \%$ for these comparisons. In all cases the TRANS98 results were well within the error limits for the biogeooptical model. The hyperbolic slope models proposed for a given depth demonstrated a greater deviation from the optical-chemical determinations than did the TRANS98 results. There was no overlap of hyperbolic slope models with the biogeo-optical predictions at the shallow station SCM2. At stations ASM1 and OM on October 24, 1995, the usual pattern was that the minerogenic scatter coefficient of hyperbolic slope model 2.7 did fall within the error limits of the biogeo-optical model. At station OM on October 21, 1995, all hyperbolic slope models fell within the error limits of the biogeo-optical model.

[43] Overall, the pattern we are seeing in the results for particle size distribution models and the Mie calculations for minerogenic scattering is the effect of overestimating large particle size classes by the hyperbolic slope models. The increase in large particle sizes, often by many orders of magnitude, as one goes from the hyperbolic slope of 2.7 to the smaller slopes greatly increases the minerogenic scattering coefficient, resulting in usually large errors of estimation.

\section{Discussion and Conclusions}

[44] Our purpose here is to evaluate the efficacy of hyperbolic slope models in making useful estimates of minerogenic particle size distributions and their minerogenic scattering coefficients for the nearshore region, within which dramatic changes in physical forcing and resuspension of bottom sediments occur. It has been shown that the changes in physical forcing can account for dramatic optical variability in the nearshore region [Keen and Stavn, 2000; Johnson et al., 2001; Weidemann et al., 1997, 2000]. The sedimentation model TRANS98, because of its solid grounding in water-sediment physics rather than empirical relationships, has been shown to give a good estimate of the minerogenic component of the hydrosol total scattering coefficient (Table 6) due to resuspended sediment (KS). Thus we use it as the baseline for predicting particle concentrations and size distributions.

[45] The trends of the distribution of particle concentration with size classes shown in Figures 4-7 are representative for all stations. The TRANS98 model predicts that particles in the midrange (near the mean of the available bed sediment shown in Figure 2) dominate resuspension near the bottom at all stations, with relatively fewer particles present in the larger and smaller size classes (e.g., Figure 5a). Thus the Gaussian lognormal trend of the particle size distributions in the bottom sediments [Inman, 1953; Limpert et al., 2001] predominates for the suspended minerogenic particulates near the bottom. At $2 \mathrm{~m}$ above the bed, the predicted particle size distributions differ between the shallowest station (SCM2) in which the smallest size class is the modal class (Figure $4 \mathrm{~b}$ ), and the other stations, which follow the trend predicted at the bottom (Figures $5 b-7 b$ ). This difference reflects the larger shear stresses in shallow water where surface waves interact strongly with the bed. At the water surface, the 50- $\mathrm{mm}$ size class is dominant at the shallower stations (Figures $4 \mathrm{c}$ and $5 \mathrm{c}$ ) whereas the $73-\mu \mathrm{m}$ class is more numerous at the deeper stations (Figures 6c and 7c). Note, however, that the number of particles in the $73-\mu \mathrm{m}$ class is larger at the 
shallow stations. This trend of the $73-\mu \mathrm{m}$ class being dominant at the surface continues to the deepest station of the optical line, not reported in this study. The distribution at the water surface of the deeper stations contains less $50-\mu \mathrm{m}$ sediment because of bed armoring; the smaller seafloor shear stresses resuspend less coarse material and thus prevent the entrainment of smaller grains, which remain trapped within the bed. More sediment is resuspended at the shallow stations, but the coarse fraction remains near the bed, producing an overall finer size distribution at the surface. In summary, the largest size classes decrease as the surface is approached whereas the smallest size class increases. Overall, the hyperbolic slope models overestimate the small size classes, underestimate midrange classes, and overestimate the large size classes. The only exceptions occur in the shallower stations where the smallest size class may be slightly underestimated by some hyperbolic slope models (Figures $3 c-5 c$ ). The largest size class is highly overestimated by the hyperbolic slope models in every case. The Gaussian lognormal distribution of particle size classes causes a hyperbolic slope model to be a poor model or estimator for mineral particle size concentrations.

[46] The overestimation and underestimation of the particle number noted above can be as great as a factor of 5 for the smaller size classes, as small as a factor of 0.36 for midrange size classes, while the larger size classes can be overestimated by 30 orders of magnitude or more. As the slope decreases in the hyperbolic slope models, the overestimation of smaller size classes decreases and even disappears with some of the shallower stations. However, the overestimate of the larger size classes in all cases increases with decreasing hyperbolic slope. It is evident, when comparing the TRANS98 baseline and the hyperbolic slope models, that there are several differences in particle size distribution with depth and between the shallower and deeper stations that a hyperbolic slope, semi-empirical, model cannot predict. Hyperbolic slope model predictions are poor even in the case of an apparent logarithmic (hyperbolic) decrease in particle concentration with diameter at the surface. That is, the estimates of particle concentration per size class do not improve when the shallow surface stations appear to show a logarithmic decrease in size classes.

[47] Why do the proposed hyperbolic slope models for the nearshore region perform so poorly? To begin with, the size distribution of a particular nearshore bottom sediment configuration is created by a complex integration of factors, both additive and multiplicative, that cannot be summarized in simplistic distribution functions. For example, the shear stresses for resuspending each size class of quartz particles differ [Roberts et al., 1998]. The supply of particles in all size classes to feed a supposed hyperbolic size distribution is finite; thus the initial availability of particle size classes in the bed, as well as armoring as smaller particles are removed [Roberts et al., 1998], must be considered in explaining the complex nature of the baseline particle size distributions reported here. Furthermore, a hyperbolic slope of less than 3 has fundamental physical problems. It is not possible to extend a hyperbolic distribution with a slope less than 3 much beyond a size limit of 4 to $10 \mu \mathrm{m}$. The volume (and therefore mass) of particles per log size increment is increasing with log size increment. Therefore the slope will have to break (and increase) beyond this size limit to prevent an eventual infinite increase of mass per logarithmic size increment. This physical argument has been elaborated by McCave [1975] and Harris [1977] while the size limits have been noted by Brun-Cottan [1971], Jerlov [1976], Bader [1970], and others.

[48] McCave $[1975,1984]$ points out that the only portion of the ocean where a simple hyperbolic size distribution may be possible is below the actively mixed surface layers of the open ocean. Here the various dynamical processes of particulate coagulation and sinking may come into equilibrium. The processes in the upper layers of the open ocean of biological productivity, influx of material originating nearshore from ring systems etc., and atmospheric fallout are separate. These individual processes cannot be rationalized or explained by one simple mathematical model. The situation is even more complicated near the coast where direct riverine influx occurs and sediment resuspension is significant.

[49] One hypothesis proposed by Schoonmaker et al. [1994] was that the particle size distribution for the Oceanside region and the rest of southern California could be described and predicted by a hyperbolic model with a slope of 2.1. They proposed that this model would be the most efficient one for estimating the scattering coefficient due to suspended mineral particulates in the coastal region. In Tables 3 and 4, comparisons from model calculations, we see that this model of slope 2.1 deviates strongly from the baseline with the exception of the bottom (4-20\%). The scattering coefficient at the surface deviates by $13-27 \%$ from the baseline. In comparisons with the available opticalchemical data (Table 6), the slope 2.1 model, for the most part, deviates significantly from the optically derived mineral scattering on 24 October but shows fair agreement on 21 October.

[50] The strongest deviations for the hyperbolic slope 2.1 model occur in the surface layer, which is of greatest importance for remote sensing. The estimate of the minerogenic backscattering coefficient at the surface, which is a direct index of efficacy for remote sensing applications, deviates by $15-26 \%$ from the baseline values (Table 5 ). The surface values for the hyperbolic model with a slope of 2.7 were more accurate for both total scattering and backscattering in the model comparisons (Tables 3, 4, and 5), as were comparisons with the optically derived minerogenic scattering values (Table 6). We conclude that the hyperbolic slope 2.1 model is not an adequate representation of near coastal water for optical purposes. The hyperbolic slope 2.7 model is more accurate than the slope 2.1 model in nearly every case with but two exceptions (see Tables 4 and 6). The hyperbolic model with a slope of 2.7 appears to be best in most cases, in direct contradiction to Schoonmaker et al. [1994], but it does overestimate the minerogenic total scattering coefficient in most cases.

[51] An additional hypothesis of Schoonmaker et al. [1994] was that a hyperbolic slope of 2.1 would be replaced by models with smaller slopes in the nearshore region and near the bottom. They proposed that larger particles would be resuspended in greater proportion to other size classes, upon approaching the shore or the bottom, and decrease the hyperbolic slope of the suspended minerogenic particle distribution. However, the shallow stations do not confirm 
this prediction. Figures 4-7 do not demonstrate proportionally more large particles being resuspended in the shallower stations than in the deeper stations for the baseline results. In Tables 3, 4, and 6, with the scattering coefficients calculated from the range of proposed hyperbolic slopes (2.1 to 1.3 ) plus the bracketing limits, the values calculated from Schoonmaker et al. [1994] are italicized. The deviations with depth range from $6 \%$ to $61 \%$ with the greater deviations occurring near the bottom for all stations, indicating a poor match with the scattering coefficients of the resuspended sediment from the baseline and from the optically derived values. Interestingly, the smaller slopes that are supposed to be better at estimating the particle distribution properties near the bottom are always overestimating the total scattering coefficient by a large amount. It is worth noting that the particle size ranges determined in the lab by Schoonmaker et al. [1994] were filtered and settled to remove large particles. Thus they were not able to directly investigate the results of large, actively scattering particles which would be rapidly entering and leaving the hydrosol in response to the physical forces resuspending them at the time. Thus hyperbolic slope models with smaller slopes (2.1 to 1.3$)$ are rather inefficient at predicting scattering coefficients for both shallower stations and at near bottom depths.

[52] The major exceptions to the trends noted above occur at station OM on 21 October 1995. We noted previously that this date demonstrated the weakest physical forcing for resuspending mineral sediment. In Table 6 the limits for the probable error of the minerogenic scattering coefficient either cause the estimate of minerogenic scattering to span the value of 0 or to put the estimate of the coefficient squarely in the region of error for the AC-9 instrument. For these very low values of the minerogenic scattering coefficient, apparently any model can provide an estimate of minerogenic scattering that falls within the probable error limits. With the relatively high error at this station the comparisons between the minerogenic scattering models are probably not adequate to reveal the trends that were observed at the other stations.

[53] Many investigators are accepting simple hyperbolic particle size distributions as physically well-established and verified [Boss et al., 2001b; Forand and Fournier, 1999; Hammond et al., 1995]. We have shown the problems with this assumption in nearshore waters. These fundamental physical problems will not go away except in the deep open ocean below the dynamic surface layers. An example of the uncritical use of hyperbolic particle size distributions is a "Junge parameter" being proposed to describe particle size distributions [Forand and Fournier, 1999; Hammond et al., 1995] on the assumption that all suspended particle distributions can be adequately described by a hyperbolic size distribution, with slope parameters ranging from 1.3 to 3 . One of the problems with such a formulation is that it is not a physically realistic description of the particle size distribution [McCave, 1975, 1984; Jonasz and Fournier, 1996, 1999; Risovic, 1993, 2002]. The use of such a parameter for estimating a scattering coefficient from a "hyperbolic size distribution" can give the right answer for the wrong reasons. That is, the errors of estimation for the minerogenic scattering coefficient in a particular situation may serendipitously cancel, as will be explained in more detail presently.
But the errors are still there; they will not necessarily cancel. The importance of using the proper particle size distribution for Mie calculations on aerosols has been emphasized by Harris [1972].

[54] For the range of hyperbolic slope models investigated here, there are too many or too few particles in the small size classes, too many in the large size classes, and too few in the midrange. This effect gets worse as the slope becomes smaller. All of the smaller size classes are then underestimated and the two largest size classes become grossly overestimated. When the larger particle concentration of the large size classes is significantly overestimated, then the total scattering coefficient is overestimated. We have noted that the hyperbolic slope models, with few exceptions, consistently overestimate the minerogenic total scattering coefficient. All of the surface results are overestimates of the minerogenic scattering and backscattering coefficients (Tables 3-6), even though we have noted that some of the baseline particle size distributions would appear to have a hyperbolic character to them. Near the bottom a minimal deviation from the baseline predictions or even an underestimate can be found (hyperbolic slope 2.1 and 2.7 models) where the size distributions have a Gaussian lognormal character. When following the trends illustrated in this report, we see that in any situation it will be possible to find some combination of hyperbolic size classes that can give a good estimate for a total scattering coefficient. However, this is done using incorrect particle size classes and balancing out the errors. This is not acceptable for the purposes of making further predictions of what the system will do under different physical forcings or to attempt a retrieval of the particle size distribution based on inverting the optical scattering properties. Finally, it is impossible to know a priori what value of $c$ should be used in equation (1), making it problematical to apply the hyperbolic models as a general descriptor of particle distributions in type II waters.

[55] Acknowledgments. R. H. S. wishes to acknowledge the support of ONR grant N00014-97-1-0812 and several previous ones in addition to the Littoral Optical Environment Program of Office of Naval Research and the Naval Research Laboratory (Program Element 62435, 73-6640). T. R. K. wishes to acknowledge support by the Office of Naval Research, Program Element 62435N.

\section{References}

Ahn, Y.-H., A. Bricaud, and A. Morel (1992), Light backscattering efficiency and related properties of some phytoplankters, Deep Sea Res., 39, $1835-1855$

Babin, M., A. Morel, V. Fournier-Sicre, F. Fell, and D. Stramske (2003), Light scattering properties of marine particles in coastal and open ocean waters as related to the particle mass concentration, Limnol. Oceanogr. $48,843-859$.

Bader, H. (1970), The hyperbolic distribution of particle sizes, J. Geophys. Res., 75, 2822-2830.

Bohren, C. F., and D. R. Huffman (1983), Absorption and Scattering of Light by Small Particles, 530 pp., John Wiley, New York.

Boss, E., W. S. Pegau, W. D. Gardner, J. R. V. Zaneveld, A. H. Barnard, M. S. Twardowski, G. C. Chang, and T. D. Dickey (2001a), Spectral particulate attenuation and particle size distribution in the bottom boundary layer of a continental shelf, J. Geophys. Res., 106(C5), 9509-9516.

Boss, E., M. S. Twardowski, and S. Herring (2001b), Shape of the particulate beam attenuation spectrum and its inversion to obtain the shape of the particulate size distribution, Appl. Opt., 40, 4885-4893.

Bricaud, A., A.-L. Bédhomme, and A. Morel (1988), Optical properties of diverse phytoplanktonic species: Experimental results and theoretical interpretation, J. Plankton Res., 10, 851-873. 
Brun-Cottan, J.-C. (1971), Étude de la granulometrie des particules marines mesures effectuées avec un compter Coulter, Cah. Océanogr., 23, $193-$ 205

Bukata, R. P., J. H. Jerome, J. E. Bruton, S. C. Jain, and H. H. Zwick (1981), Optical water quality model of Lake Ontario: 1. Determination of the optical cross sections of organic and inorganic particulates in Lake Ontario, Appl. Opt., 20, 1696-1703.

Bukata, R. P., J. H. Jerome, K. Y. Kondratyev, and D. V. Pozdnayakov (1995), Optical Properties and Remote Sensing of Inland and Coastal Waters, 362 pp., CRC, Boca Raton, Fla.

Cho, B. C., and F. Azam (1990), Biogeochemical significance of bacterial biomass in the ocean's euphotic zone, Mar. Ecol. Prog. Ser., 63, $253-$ 259.

Cole, J. J., F. Findlay, and M. L. Pace (1988), Bacterial production in fresh and saltwater ecosystems: A cross-system overview, Mar. Ecol. Prog. Ser. 43, 1-10.

Forand, J. L., and G. R. Fournier (1999), Particle distributions and index of refraction estimation for Canadian waters, in Airborne and In-water Underwater Imaging, Proc. SPIE, vol. 3761, edited by G. D. Gilbert, pp. 34-61, SPIE-The Int. Soc. for Opt. Eng., Bellingham, Wash.

Gallie, E. A., and P. A. Murtha (1992), Specific absorption and backscattering spectra for suspended minerals and chlorophyll-a in Chilko Lake, British Columbia, Remote Sens. Environ., 39, 103-118.

Glenn, S. M., and W. D. Grant (1987), A suspended sediment correction for combined wave and current flows, J. Geophys. Res., 92, 82448246

Gordon, H. R., and A. Y. Morel (1983), Remote Assessment of Ocean Color for Interpretation of Satellite Visible Imagery: A Review, Lecture Notes Coastal Estuarine Stud., edited by R. T. Barber et al., Springer-Verlag, New York.

Gould, R. W., Jr., R. A. Arnone, and P. M. Martinolich (1999), Spectral dependence of the scattering coefficient in Case 1 and Case 2 waters, Appl. Opt., 38, 2377-2383.

Green, R. E., H. M. Sosik, and R. J. Olson (2003), Contributions of phytoplankton and other particles to inherent optical properties in New England continental shelf waters, Limnol. Oceanogr., 48, 2377-2391.

Hammond, R. R., S. A. Jenkins, J. S. Cleveland, J. C. Talcott, A. L. Heath J. Wasyl, S. G. Goosby, K. F. Schmitt, L. A. Levin, and B. MacRitchie (1995), Coastal water clarity modeling feasibility study, Final report, SAIC Tech. Rep. 01-1349-03-4841-000 (CDRL A002), xii + 263 pp., Tech. Res. Group, SAIC, San Diego, Calif

Harris, F. S. (1972), Calculated Mie scattering properties in the visible and infrared of measured Los Angeles aerosol size distributions, Appl. Opt., $11,2697-2705$

Harris, J. E. (1977), Characterization of suspended matter in the Gulf of Mexico: II. Particle size analysis of suspended matter from deep water, Deep Sea Res., 24, 1055-1061.

Hill, P. S., R. M. Nowell, and P. A. Jumars (1988), Flume evaluation of the relationship between suspended sediment concentration and excess boundary shear stress, J. Geophys. Res., 93, 12,499-12,509.

Inman, D. L. (1953), Areal and seasonal variations in beach and near shore sediments at La Jolla, California, Tech. Memo. 39, 82 pp., U.S. Beach Erosion Board, Washington, D. C.

Jerlov, N. G. (1976), Marine Optics, 2nd ed., 231 pp., Elsevier Sci., New York.

Johnson, D. R., A. Weidemann, and W. S. Pegau (2001), Internal tidal bores and bottom nepheloid layers, Cont. Shelf Res., 21, 1473-1484.

Jonasz, M. (1986), Role of nonsphericity of marine particles in light scattering and a comparison of results of its determination using SEM and two types of particle counters, in Ocean Optics VIII, Proc. SPIE, vol. 637, edited by M. A. Blizard, pp. 148-154, SPIE-The Int. Soc. for Opt. Eng., Bellingham, Wash.

Jonasz, M. (1991), Size, shape, composition, and structure of microparticles from light scattering, in Principles, Methods, and Application of Particle Size Analysis, edited by J. P. M. Syvitski, pp. 143-162, Cambridge Univ. Press, New York.

Jonasz, M., and G. Fournier (1996), Approximation of the size distribution of marine particles by a sum of log-normal functions, Limnol. Oceanogr., $41,744-754$.

Jonasz, M., and G. Fournier (1999), Approximation of the size distribution of marine particles by a sum of log-normal functions (Errata: Corrections and additional results), Limnol. Oceanogr., 44, 1358.

Junge, C. E. (1969), Comments on "Concentration and size distribution measurements of atmospheric aerosols and a test of the theory of selfpreserving size distributions," J. Atmos. Sci., 26, 603-608.

Keen, T. R., and S. M. Glenn (1998), Resuspension and advection of sediment during Hurricane Andrew on the Louisiana continental shelf, in 5th International Conference on Estuarine and Coastal Modeling, edited by M. L. Spaulding and A. Blumberg, pp. 481-494, Am. Soc. of Civ. Eng., Reston, Va.
Keen, T. R., and R. L. Slingerland (1993), A numerical study of sediment transport and event bed genesis during tropical storm Delia, J. Geophys. Res., 98, 4775-4791.

Keen, T. R., and R. H. Stavn (2000), Developing a capability to forecast coastal ocean optics: Minerogenic scattering, in 6th International Conference on Estuarine and Coastal Modeling, edited by M. L. Spaulding and H. L. Butler, pp. 178-193, Am. Soc. of Civ. Eng., Reston, Va.

Kitchen, J. C., and J. R. V. Zaneveld (1990), On the noncorrelation of the vertical structure of light scattering and chlorophyll $a$ in case I waters, J. Geophys. Res., 95, 20,236-20,245.

Kullenberg, G. (1974), Observed and computed scattering functions, in Optical Aspects of Oceanography, edited by N. Jerlov and E. SteemanNielsen, pp. 25-49, Academic, San Diego.

Limpert, E., W. A. Stahel, and M. Abbt (2001), Log-normal distributions across the sciences: Keys and clues, BioScience, 51(5), 341-352.

Loisel, H., and A. Morel (1998), Light scattering and chlorophyll concentration in case 1 waters: A reexamination, Limnol. Oceanogr., 43, 847-858.

Maffione, R. A., and D. R. Dana (1997), Instruments and methods for measuring the backward-scattering coefficient of ocean waters, Appl. Opt., 36, 6057-6067.

McCartney, E. J. (1976), Optics of the Atmosphere: Scattering by Molecules and Particles, John Wiley, New York.

McCave, I. N. (1975), Vertical flux of particles in the ocean, Deep Sea Res., $22,491-502$

McCave, I. N. (1984), Size spectra and aggregation of suspended particles in the deep ocean, Deep Sea Res., 31, 329-352.

Morel, A. (1987), Chlorophyll-specific scattering coefficient of phytoplankton: A simplified theoretical approach, Deep Sea Res., 34, 1093-1105.

Morel, A., and Y. H. Ahn (1990), Optical efficiency factors of free-living marine bacteria: Influence of bacterioplankton upon the optical properties and particulate organic carbon in oceanic waters, J. Mar. Res., 48, 145175

Morel, A., and Y. H. Ahn (1991), Optics of heterotrophic nanoflagellates and ciliates: A tentative assessment of their scattering role in oceanic waters compared to those of bacterial and algal cells, J. Mar. Res., 49, $177-202$

Morel, A., and L. Prieur (1977), Analysis of variations in ocean color, Limnol. Oceanogr., 22, 709-722.

Myint, S. W., and N. D. Walker (2002), Quantification of surface suspended sediments along a river dominated coast with NOAA AVHRR and SeaWIFS measurements: Louisiana, USA, Int. J. Remote Sens., 23(16), 3229-3249

Petzold, T. J. (1972), Volume scattering functions for selected ocean waters, SIO Ref. 72-78, Scripps Inst. of Oceanogr., La Jolla, Calif.

Risovic, D. (1993), Two component model of sea particle size distribution, Deep Sea Res., Part I, 40, 1459-1473.

Risovic, D. (2002), Effect of suspended particulate-size distribution on the backscattering ratio in the remote sensing of seawater, Appl. Opt., 41, $7092-7101$

Roberts, J., R. Jepsen, D. Gotthard, and W. Lick (1998), Effects of particle size and bulk density on erosion of quartz particles, J. Hydraul. Engr. 124, 1261-1267.

Roesler, C. (1995), The influence of particulate and dissolved material on water clarity in the littoral zone, data report for grant N00014-95-1-G909, Naval Res. Lab., Stennis Space Center, Miss.

Schoonmaker, J. S., R. R. Hammond, A. L. Heath, and J. S. Cleveland (1994), A numerical model for prediction of sub-littoral optical visibility, in Ocean Optics XII, Proc. SPIE, vol. 2258, edited by J. S. Jaffe, pp. 685-702, SPIE-The Int. Soc. for Opt. Eng., Bellingham, Wash.

Shifrin, K. S. (1988), Physical Optics of Ocean Water, pp. 1-285, Am. Inst. of Phys., New York.

Smith, R. C., and K. S. Baker (1978), Optical classification of natural waters, Limnol. Oceanogr., 23, 260-267.

Stavn, R. H., and A. D. Weidemann (1997), Coastal optical water type 2: Modeling and minerogenic scattering, in Ocean Optics XIII, Proc. SPIE, vol. 2963, edited by S. G. Ackleson and R. Frouin, pp. 38-48, SPIEThe Int. Soc. for Opt. Eng., Bellingham, Wash.

Stramski, D., and D. A. Kiefer (1990), Optical properties of marine bacteria, in Ocean Optics X, Proc. SPIE, vol. 1302, edited by R. W. Spinrad, pp. 250-268, SPIE-The Int. Soc. for Opt. Eng., Bellingham, Wash.

Stumpf, R. P., and J. R. Pennock (1989), Calibration of a general optical equation for remote sensing of suspended sediments in a moderately turbid estuary, J. Geophys. Res., 94(C10), 14,363-14,371.

Styles, R. B. (1998), A continental shelf bottom boundary layer model: Development, calibration, and applications to sediment transport in the Middle Atlantic Bight, Ph.D. thesis, 261 pp., Rutgers Univ., New Brunswick, N. J.

Sydor, M., and R. A. Arnone (1997), Effect of suspended particulate and dissolved organic matter on remote sensing of coastal and riverine waters, Appl. Opt., 36, 6905-6912. 
Tanner, W. F. (1969), The particle size scale, J. Sediment. Petrol., 39, 809812

Tassan, S. (1994), Local algorithms using SeaWiFS data for the retrieval of phytoplankton, pigments, suspended sediment and yellow substance in coastal waters, Appl. Opt., 33, 2369-2378.

Taylor, J. R. (1982), An Introduction to Error Analysis, 270 pp., Univ. Sci., Mill Valley, Calif.

Twardowski, M. S., E. Boss, J. B. Macdonald, W. S. Pegau, A. H. Barnard and J. R. V. Zaneveld (2001), A model for estimating bulk refractive index from the optical backscattering ratio and the implications for understanding particle composition in case I and case II waters, J. Geophys. Res., 106(C7), 14,143-14,163.

Ulloa, O., S. Sathyendranath, and T. Platt (1994), Effect of the particle-size distribution on the backscattering ratio in seawater, Appl. Opt., 33, 70707077.

Walker, N. (2001), Tropical storm and hurricane wind effects on water level, salinity, and sediment transport in the river-influenced Atchafalaya-Vermilion Bay system, Louisiana, USA, Estuaries, 24(4), 498-508. Weidemann, A. D., W. S. Pegau, L. A. Jugan, and T. E. Bowers (1997), Tidal influences on optical variability in shallow water, in
Ocean Optics XIII, Proc. SPIE, vol. 2963, edited by S. G. Ackleson and R. Frouin, pp. 320-325, SPIE-The Int. Soc. for Opt. Eng., Bellingham.

Weidemann, A. D., D. J. Johnson, R. J. Holyer, W. S. Pegau, L. A. Jugan, and J. C. Sandidge (2000), Remote imaging of internal solitons in the coastal ocean, Remote Sensing Environ., 76, 260-267.

Wiscombe, W. J. (1979), Mie scattering calculations: Advances in technique and fast, vector-speed computer codes, NCAR Tech. Note TN$140+$ STR, $1-62$.

Zaneveld, J. R. V., and J. C. Kitchen (1995), The variation in the inherent optical properties of phytoplankton near an absorption peak as determined by various models of cell structure, J. Geophys. Res., 100(C7), $13,309-13,320$

T. R. Keen, Oceanography Division, Naval Research Laboratory, Stennis Space Center, MS 39529-5004, USA.

R. H. Stavn, Department of Biology, University of North Carolina at Greensboro, Greensboro, NC 27402-6174, USA. (stavnr@uncg.edu) 